\title{
Partial Factor IX Protein in a Pedigree with Hemophilia B Due to a Partial Gene Deletion
}

\author{
Gordon L. Bray and Arthur R. Thompson \\ Division of Hematology, Departments of Medicine and Pediatrics, University of Washington School of Medicine \\ and the Pacific Medical Center, Seattle, WA 98144
}

\begin{abstract}
A partial gene product was identified in a pedigree with hemophilia $B$ due to a partial deletion of the Factor IX gene (Chen, S.-H., S. Yoshitake, P. F. Chance, G. L. Bray, A. R. Thompson, C. R. Scott, and K. Kurachi, 1985, J. Clin. Invest., 76:21612164.). Levels of this mutant protein in plasma of affected family members studied ranged from 24 to $36 \mathrm{ng} / \mathrm{ml}(0.6-0.9 \mathrm{U} / \mathrm{dl}$ or percent of normal) by a solid-phase immunoassay which is sensitive and specific for the calcium-dependent conformation of human Factor IX. No Factor IX antigen could be detected in patients' plasmas by a non-calcium-requiring monoclonal antiFactor IX antibody ( $<2 \mathrm{ng} / \mathrm{ml})$. The unconcentrated urine from the five affected family members and four obligate heterozygotes tested contained calcium-dependent Factor IX antigen levels ranging from 64 to $160 \mathrm{ng} / \mathrm{ml}(1.6-4.0 \mathrm{U} / \mathrm{dl})$ and from 10 to 68 $\mathrm{ng} / \mathrm{ml}(0.25-1.7 \mathrm{U} / \mathrm{dl})$, respectively. Of nine normal volunteers screened, three had detectable calcium-dependent antigen in unconcentrated first morning-voided urines with $9.6-16.8 \mathrm{ng} / \mathrm{ml}$ (0.24-0.42 U/dl), while the remaining six had detectable urinary antigen only after a 10 -fold concentration.

Abnormal and normal urinary Factor IX antigen species were concentrated, immunoaffinity purified, electrophoresed, immunoblotted, and distinguished by autoradiography after incubation with ${ }^{125}$ I-polyclonal calcium-requiring anti-Factor IX. After reducing purified or concentrated samples, a single abnormal 36,000-mol-wt band was identified in the urines from the four affected family members and four obligate heterozygotes tested. Electrophoresis of the reduced urinary Factor IX antigen from the one normal subject tested showed a broad 15,000-20,000mol-wt band. This normal band was smaller than the species in patients' urines, and was seen as a minor component in the samples from the heterozygotes. No abnormal antigen could be detected in urine from the two other female family members tested. Thus, abnormal urinary Factor IX antigen represents a marker for the presence of the hemophilic Factor IX gene in this family.
\end{abstract}

\section{Introduction}

Hereditary deficiency of Factor IX, hemophilia B, is an X-linked disorder characterized by recurrent bleeding episodes. Approx-

A preliminary report of this work has appeared in abstract form (1985. Clin. Res. 33:544a).

Dr. Bray's current address is Division of Hematology, Children's Hospital National Medical Center, 111 Michigan Ave. N.W., Washington, DC 20006. Address correspondence to Dr. Thompson, Pacific Medical Center, 1200-12th Ave. S., Seattle, WA 98144.

Received for publication 2 August 1985 and in revised form 8 November 1985.

J. Clin. Invest.

(c) The American Society for Clinical Investigation, Inc.

0021-9738/86/04/1194/07 \$1.00

Volume 77, April 1986, 1194-1200 imately one-third of affected individuals have severe disease and exhibit spontaneous bleeding without a history of antecedent injury. While the clinical features of hemophilia A (Factor VIII deficiency) and hemophilia B are virtually identical, they are distinguished by the deficient clotting factor and by the blood component used for replacement therapy. Another distinction is the prevalence of acquired inhibitors. Approximately $15 \%$ of individuals with severe hemophilia A develop anti-Factor VIII antibodies after therapy, usually by early adulthood (1). In contrast, the incidence of inhibitors in hemophilia B is decidedly lower, occurring in $2.5 \%$ (1), or less, of severely affected individuals. One explanation for a lower incidence is that most patients with hemophilia B have at least low levels of Factor IX antigen in their plasma $(2,3)$.

Direct gene analysis has been applied to the study of hemophilia B patients with inhibitors. DNA from six inhibitor patients in five different pedigrees has demonstrated gross deletions in the Factor IX gene among all but one $(4,5)$. More recently, Chen et al. (6) have identified a partial gene deletion occurring in two cousins with severe hemophilia B and no inhibitor. This deletion, $\sim 10$ kilobases $(\mathbf{k b})^{1}$ in length, is located in the middle third of the Factor IX gene, with those regions flanking the deletion appearing grossly intact by Southern blot analysis. Although nucleotide sequencing has not yet localized the deletion site (6), it is reasonable to assume that the portion of the gene $5^{\prime}$ to the deletion is structurally intact. This portion of the gene includes the signal for peptide initiation and a leader sequence in the first exon, the pro-sequence and divalent metal binding, $\gamma$-carboxyglutamyl (Gla), domain as coded for by the second and third exons, and the first of two epidermal growth factor homologous regions as coded for by the fourth exon (2). It was hypothesized that affected individuals from this pedigree might synthesize a partial gene product, a portion of which would consist of the intact Gla region, capable of assuming its normal conformational change in the presence of calcium. If secreted into plasma, the mutant gene product should be of sufficiently low molecular weight to be filtered by the kidneys and excreted into urine.

To screen for this abnormal Factor IX protein, a sensitive solid-phase immunoassay, which is highly specific for the calcium-dependent ${ }^{2}$ conformation of native Factor IX, was employed. Low levels of Factor IX were detected in the baseline plasma from four patients and in the urines from five patients and four obligate heterozygotes tested. An unanticipated finding was the presence of trace amounts of Factor IX antigen in urines

1. Abbreviations used in this paper: $\mathrm{CNBr}$, cyanogen bromide; kb, kilobases; MES, $2(N$-morphilino)ethane sulfonic acid.

2. For purposes of this manuscript, the term calcium-dependent refers to the conformation of native Factor IX antigen and its levels by immunoradiometric assays in the presence of calcium; the term calciumrequiring is applied to polyclonal antibody fractions or monoclonal antibodies that will only interact with Factor IX antigen when it has assumed its calcium-dependent conformation. 
from normal individuals. Normal and hemophilic urinary Factor IX antigens were then purified and partially characterized.

\section{Methods}

Materials. Chemicals were purchased from the following sources: acrylamide from Serva Fine Biochemicals Inc., Garden City Park, NY; sodium dodecyl sulfate-polyacrylamide gel electrophoresis low molecular weight protein standards, Coomassie Blue R-250, sodium dodecyl sulfate, $N, N, N^{\prime}, N^{\prime}$-tetramethylethylenediamine, nitrocellulose, and ammonium persulfate from Bio-Rad Laboratories, Richmond, CA; bovine albumin (fraction V), dithiothreitol, rabbit brain cephalin, trizma base, $2(\mathrm{~N}$-morpholino)ethane sulfonic acid (MES), and heparin from Sigma Chemical Co., St. Louis, MO; bis-acrylamide and chloramine T from Eastman Kodak Co., Rochester, NY; sodium ${ }^{125}$ I-iodide from New England Nuclear, Boston, MA; kaolin from Fisher Scientific Co., Pittsburgh, PA; Freund's adjuvants, from Difco Laboratories Inc., Detroit, $\mathrm{MI} ; \mathrm{Al}(\mathrm{OH})_{3}$ (Amphogel, unflavored) from Wyeth Laboratories, Philadelphia, PA; benzamidine $\mathrm{HCl}$ from Aldrich Chemical Co., Inc., Milwaukee, WI; cyanogen bromide (CNBr)-activated Sepharose 4B, CL-Sepharose 4B, and protein A CL-Sepharose 4B from Pharmacia Fine Chemicals, Piscataway, NJ. All other chemicals were reagent grade or better.

Human Factor IX was purified as described (7). For some studies, a preparation generously provided by Dr. Walter Kisiel, Department of Biochemistry, University of New Mexico, Albuquerque, NM, was used. These preparations migrated as single bands on polyacrylamide gels in the presence of sodium dodecyl sulfate. Factor IX was radioiodinated by the chloramine $\mathrm{T}$ method as described (7), but modified to employ $400 \mu \mathrm{Ci} \mathrm{Na}{ }^{125}$ in a $40-\mu \mathrm{l}$ vol and a 60 -s reaction time. The average radioactivity of this preparation was $9.0 \times 10^{5} \mathrm{cpm} / \mu \mathrm{g}$ of protein. Coupling of the Factor IX preparation to $\mathrm{CNBr}$-activated Sepharose 4B (1.4 $\mathrm{mg} / \mathrm{ml}$ wet gel) was performed according to the manufacturer's instructions. Normal citrated human plasma was obtained from volunteer blood donors and consisted of a pool of at least ten.

Patient and heterozygote characteristics. All affected individuals belong to the same generation (III) and are the progeny of four sisters (Fig. 1). Their bleeding episodes respond to Factor IX concentrate and each patient has been multiply transfused for bleeding events up to 35 times per year. To date, none has exhibited chronic complications of hemophilia. Despite the partial gene deletion (6), plasma samples from the five affected individuals available for study (III-4, III-6-9) tested negatively for the presence of Factor IX inhibitory activity (8). None of the five obligate heterozygotes (I-1, II-2, II-4-6) has experienced abnormal bleeding and the four heterozygotes tested (I-1, II-4-6) are also heterozygous for the Taq I restriction fragment length polymorphism found in affected members (6). Of the three potential heterozygotes, subject II1 is a noncarrier by Southern blot analysis of Factor IX genomic DNA

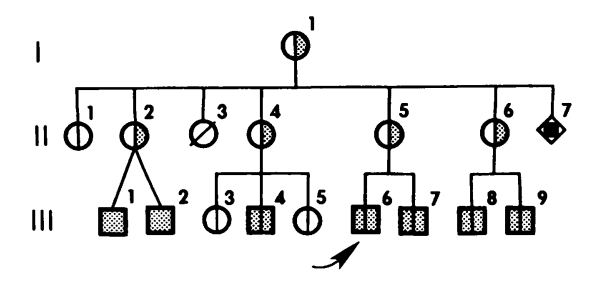

Figure 1. Representation of the hemophilia B pedigree. All seven affected family members (stippled segment) belong to generation III. Obligate heterozygotes are noted by half-stippled symbols; the vertical line indicates plasma, urine, or both were tested in the present study. Circles are for females and squares, males. Individual III-3 died at age 3 of a congenital heart defect while III-7 was a stillborn male. Note that the carrier status of family members III-3 and III-5 has not yet been determined by DNA analysis. The propositus $(\uparrow)$ was born in Seattle and followed by the local hemophilia care program since birth. Individual II-1, the eldest daughter, was incorrectly represented as the youngest in a previous figure (6).
(6), whereas family members III-3 and III-5 will not be having DNA analysis until they are older.

Samples and clotting assays. Samples were collected after receiving informed consent under a protocol approved by the University of Washington's Human Subjects Review Committee. Blood was drawn into syringes containing either sodium heparin $(100 \mathrm{U} / 10-20 \mathrm{ml})$ or onetenth volume $3.8 \%$ trisodium citrate. Anticoagulated blood was centrifuged at $12,000 \mathrm{~g}$ for $10 \mathrm{~min}$ at $4^{\circ} \mathrm{C}$; plasma was rendered platelet-poor by a second centrifugation at $48,000 \mathrm{~g}$ for $20 \mathrm{~min}$. Aliquots of citrated or heparinized platelet-poor plasma were frozen and stored at $-70^{\circ} \mathrm{C}$ until ready for use. Some plasma samples on heterozygotes were stored for up to 8 yr before being re-studied; results were essentially the same as those from current plasma samples. Plasma from four of the five affected family members studied was obtained at least $2 \mathrm{wk}$ after their last transfusion with Factor IX concentrate; subject III-9's sample came 2 mo after his last treatment. Plasma from family member III-4 was only tested for the presence of Factor IX inhibitors because the frequency with which he was being transfused for bleeding precluded baseline antigen level determinations.

Levels of Factor IX procoagulant activity in citrated plasma were determined by a modification of the one-stage, kaolin-activated partial thromboplastin time (9) employing congenitally deficient substrate plasma with $<40 \mathrm{ng} / \mathrm{ml}$ (1 U/dl) Factor IX antigen. Inhibitor titer assays were performed using citrated plasma, employing the method described by Kasper (8), but were modified by incubating for only $30 \mathrm{~min}$ before assay. The control incubation consisted of equal volumes of normal plasma and $0.15 \mathrm{M} \mathrm{NaCl}$. An IgG fraction was prepared from plasma from patient III-6, by employing a modification of methods described by Kessler (10). Briefly, $15 \mathrm{ml}$ heparinized plasma, previously adsorbed with one-tenth volume $\mathrm{Al}(\mathrm{OH})_{3}$ suspension, was applied to a $1.5 \times 0.9$ $\mathrm{cm}$ staphylococcal protein A CL-Sepharose 4B column, equilibrated in and washed with $0.1 \mathrm{M} \mathrm{NaCl}, 50 \mathrm{mM}$ Tris, $\mathrm{pH}$ 7.5. An IgG fraction was eluted from the column with $3 \mathrm{M} \mathrm{KSCN}$ and subsequently dialyzed for $48 \mathrm{~h}$ against 2 liters $0.1 \mathrm{M} \mathrm{NaHCO}_{3}, \mathrm{pH} 9.5$, before assay.

Preparation of purified polyclonal anti-human Factor IX antibody fractions. Rabbit anti-human Factor IX antibody was prepared by a modification of previously described methods (7). For immunization purposes, $5 \mathrm{mM} \mathrm{CaCl}_{2}$ (final concentration) was added to the Factor IX preparation before being emulsified in Freund's adjuvants. Immune sera obtained after secondary immunization were fractionated by affinity chromatography similar to the procedure of Liebman et al. (11), employing a $1 \times 9.5-\mathrm{cm}$ bed volume column of Factor IX-Sepharose 4B previously equilibrated in $0.1 \mathrm{M} \mathrm{NaCl}, 50 \mathrm{mM}$ Tris, $\mathrm{pH} 7.5$, with $5 \mathrm{mM}$ $\mathrm{CaCl}_{2}$. Calcium-requiring anti-Factor IX fractions were eluted in the same buffer with $5 \mathrm{mM}$ EDTA instead of $\mathrm{CaCl}_{2}$. Non-calcium-requiring fractions that remained bound to the column were then eluted in $0.1 \mathrm{M}$ glycine- $\mathrm{HCl}, \mathrm{pH} 2.5$, pooled, and dialyzed overnight against 1 liter 0.1 $\mathrm{M} \mathrm{NaCl}, 50 \mathrm{mM}$ Tris, $\mathrm{pH}$ 7.5.

Purified calcium-requiring antibody fractions were pooled and concentrated approximately fourfold by pressure dialysis in a 10-ml ultrafiltration cell with a PM-30 membrane (Amicon Corp., Danvers, MA). The concentrated preparation was radioiodinated by the chloramine $T$ method to an average radioactivity of $1.3 \times 10^{4} \mathrm{cpm} / \mu \mathrm{g}$ protein or was coupled to CNBr-activated Sepharose 4B $(0.6 \mathrm{mg}$ protein $/ \mathrm{ml}$ wet gel $)$. The polyclonal, non-calcium-requiring anti-Factor IX preparation was radioiodinated to an average radioactivity of $2.9 \times 10^{4} \mathrm{cpm} / \mu \mathrm{g}$ protein

Monoclonal antibodies. A non-calcium-requiring monoclonal antiFactor IX which binds to an epitope on the heavy chain of Factor IXa (3) was employed as the solid-phase antibody in some immunoassays (see below) and was also radioiodinated by the chloramine $\mathrm{T}$ method (7) using 1 -min incubations $\left(2.7 \times 10^{3} \mathrm{cpm} / \mu \mathrm{g}\right.$ protein $)$. A monoclonal calcium-requiring anti-factor IX which reacts with a Factor IXa light chain epitope, was generously provided by Dr. Kenneth Smith, Departments of Pathology and Medicine, University of New Mexico, Albuquerque, NM (12). The antibody preparation was coupled to $\mathrm{CNBr}$ activated Sepharose 4B $(3.0 \mathrm{mg} / \mathrm{ml}$ wet gel) for immunoaffinity purifcation of urinary Factor IX antigen as described below.

Concentration and purification of urinary Factor IX antigen. Efforts 
to purify calcium-dependent antigen from the plasma of affected individuals were limited by the low levels in their plasma and by the amount of plasma available. Insofar as Factor IX antigen was present at higher levels in urine than in plasma from these individuals, mutant Factor IX was concentrated and purified from urine.

Urine was sampled as a first morning void in all individuals studied except for four patients and two obligate heterozygotes from whom up to 2 liters of urine were collected into 1-5 mM benzamidine (final concentration) for up to $5 \mathrm{~d}$; the latter was stored at $4^{\circ} \mathrm{C}$ during the collection period. Among affected family members, no Factor IX concentrate was infused for a period of at least $7 \mathrm{~d}$ before the beginning of the urine collection and throughout the collection period. Urine was centrifuged at $12,000 \mathrm{~g}$ for $10 \mathrm{~min}$ in order to render it poor of cells, salts, and debris. Supernatant urine was subsequently frozen at $-70^{\circ} \mathrm{C}$ until use. Upon thawing, it was occasionally necessary to centrifuge the urine to remove precipitated salts. Urine $\mathrm{pHs}$ were between 5.3 and 6.8.

Single-void urines were concentrated $10-100$-fold in $10-\mathrm{ml}$ or $50-\mathrm{ml}$ ultrafiltration cells. For the larger volume preparations, urine was concentrated 100-200-fold using first a 375-ml and then a 50-ml ultrafiltration cell. Either PM-10 or YM-10 Diaflo membranes (Amicon Corp., Scientific Systems Div., Danvers, MA) were used. After initial concentration, the urine was twice diluted 10 -fold with $0.1 \mathrm{M} \mathrm{NaCl}, 50 \mathrm{mM}$ Tris, pH 7.5, containing $0.01 \%$ bovine serum albumin and $1 \mathrm{mM}$ benzamidine and the volume subsequently reduced by pressure dialysis. $\mathrm{CaCl}_{2}$ was added at a final concentration of $10 \mathrm{mM}$ to each concentrated urine sample before affinity chromatography.

For immunoaffinity purification, either a polyclonal, calcium-requiring anti-Factor IX Sepharose $4 \mathrm{~B}$ column $(1.5 \times 6.4 \mathrm{~cm})$ or a monoclonal calcium-requiring anti-Factor IX Sepharose $4 B$ column $(1.4 \times 5.7$ $\mathrm{cm}$ ) was employed. These were equilibrated with $50 \mathrm{mM}$ Tris, $\mathrm{pH} 7.5$, $5 \mathrm{mM} \mathrm{CaCl}_{2}$ containing $0.1 \mathrm{M} \mathrm{NaCl}$ or $0.5 \mathrm{M} \mathrm{NaCl}$, respectively. The columns were washed with the respective calcium-containing equilibration buffers until the absorbance at $280 \mathrm{~nm}$ of the column effluent was $<0.02$. The columns were then washed with $20-30 \mathrm{ml}$ of $0.1 \mathrm{M} \mathrm{NaCl}$, $50 \mathrm{mM}$ Tris, $\mathrm{pH} 7.5,2 \mathrm{mM} \mathrm{CaCl}_{2}$. Factor IX antigen was eluted in 0.1 $\mathrm{M} \mathrm{NaCl}, 50 \mathrm{mM}$ Tris, $\mathrm{pH} 7.5,5 \mathrm{mM}$ EDTA. 1-ml fractions of the EDTA eluate were collected and screened for antigen by polyclonal calciumrequiring and monoclonal non-calcium-requiring immunoradiometric assays described below. Upon completion of each stepwise calcium-dependent adsorption and EDTA elution of urinary Factor IX antigen, the columns were washed with $1.0 \mathrm{M} \mathrm{NaCl}, 50 \mathrm{mM}$ Tris, pH 7.5, $5 \mathrm{mM}$ EDTA and, subsequently, the equilibration buffer. For some studies, antigen-containing fractions were pooled and concentration attempted by ultrafiltration using a YM-2 filter (Amicon Corp.).

Immunoradiometric assays. Levels of urinary factor IX antigen were determined by modifications of recently described assays $(3,13)$. Briefly, monoclonal non-calcium-requiring, anti-Factor IX or polyclonal calcium-requiring anti-Factor IX were diluted 200 -fold in $0.1 \mathrm{M} \mathrm{Na} \mathrm{HCO}_{3}$, pH 9.5, before being adsorbed to microtiter wells (Imulon-1 Removastrip; Dynatech Laboratories, Inc., Dynatech Corp., Alexandria, VA). Polyclonal non-calcium-requiring anti-Factor IX was diluted 80 -fold and monoclonal calcium-requiring antibody was diluted 20 -fold in the bicarbonate buffer before adsorption to wells. $50 \mathrm{mM}$ Tris, pH 7.5, was substituted for phosphate in all buffer solutions used for sample dilution and washes; where indicated, these contained $5 \mathrm{mM} \mathrm{CaCl}_{2}$. Dilutions of normal plasma and test plasmas or urines were incubated overnight in antibody-coated wells and were followed by a 6-h incubation with radiolabeled antibody. Patient plasma and urine samples were run on at least two separate occasions for each assay; at least four dilutions of patient plasma or urine were run and compared with data obtained from a simultaneously run standard curve of pooled normal human plasma. Data were plotted as log dilution vs. logistic probability of percent counts per minute bound in each well. Coefficients of variation for duplicate determinations were $<7 \%$; nonspecific binding was $<1 \%$.

Gel electrophoresis. Electrophoresis was performed in the presence of sodium dodecyl sulfate on $10 \%$ polyacrylamide gels as described by Weber and Osborn (14); for some experiments, slab gels were prepared and run as previously described (3). Polyacrylamide slabs were blotted electrophoretically onto nitrocellulose paper in a methanol-containing
Tris-glycine buffer (15). Strips of nitrocellulose paper were incubated for $1 \mathrm{~h}$ with radiolabeled anti-Factor IX preparations $\left(1.0-2.0 \times 10^{5} \mathrm{cpm} /\right.$ $\mathrm{ml}$ ), dried, and autoradiographed as described (13). For calcium-requiring antibody preparations, all blocking, incubation, and rinsing solutions contained $\mathrm{CaCl}_{2}$ at a final concentration of $10 \mathrm{mM}$. Molecular weights were estimated by comparison with the relative anodal migration of simultaneously run protein standards stained with Coomassie Blue. These included: phosphorylase B $(92,500 \mathrm{~mol} \mathrm{wt})$, bovine serum albumin $(66,200 \mathrm{~mol} \mathrm{wt})$, ovalbumin $(45,000 \mathrm{~mol} \mathrm{wt})$, carbonic anhydrase $(31,000$ mol wt), soybean trypsin inhibitor (21,500 mol wt), and lysozyme $(14,400$ mol wt).

\section{Results}

Inhibitor assays. As noted in Methods, plasma samples from the five affected individuals tested exhibited no Factor IX inhibitory activity after preincubation with pooled normal human plasma. The other two affected individuals live out of the area and have not been screened with formal inhibitor testing, although clinically, their bleeding episodes are reported as responding well to conventional doses of Factor IX concentrates. In an attempt to screen for either a low level alloantibody or one which does not inactivate Factor IX, the staphylococcol protein A-purified IgG fraction (absorbance at $280 \mathrm{~nm}=2.5$ ) from patient III-6's plasma was adsorbed to microtiter wells either undiluted or diluted 10 - and 100 -fold in $0.1 \mathrm{M} \mathrm{NaHCO}_{3}, \mathrm{pH}$ 9.5. Only negligible binding (1.1-1.5\%) of ${ }^{125} \mathrm{I}-$ Factor IX $(20,000$ $\mathrm{cpm} /$ well) was noted at any of the three concentrations of this purified IgG fraction after $3 \mathrm{~h}$ at $37^{\circ} \mathrm{C}$.

Immunoassay employing polyclonal calcium-requiring antiFactor IX antibody. When wells were coated with polyclonal calcium-requiring anti-Factor IX and the final incubation employed the ${ }^{125}$ I preparation of this antibody, dilution curves of normal human plasma gave a direct linear dose response to a concentration of $4 \mathrm{ng} / \mathrm{ml}$ Factor IX (i.e., $0.1 \mathrm{U} / \mathrm{dl}$ ). Dilutions of purified Factor IX rendered a curve which was parallel to that obtained using pooled normal human plasma. Later preparations of radiolabeled antibody with higher specific radioactivities resulted in sensitivity to $2 \mathrm{ng} / \mathrm{ml}$. When the assay was run in the presence of $5 \mathrm{mM}$ EDTA instead of $\mathrm{CaCl}_{2}$, binding of ${ }^{125}$ I-antibody was consistently $<0.5 \%$ of total counts per minute added at all plasma dilutions.

Polyclonal calcium-requiring antibody was $>99.9 \%$ specific for Factor IX since $<2 \mathrm{ng} / \mathrm{ml}$ antigen was present in the plasma of an individual with severe hemophilia B. Factor IX antigen in this plasma has been consistently undetectable by immunoassays employing several non-calcium-requiring monoclonal and polyclonal anti-Factor IX antibodies $(3,7)$.

Plasma Factor IX procoagulant activities and antigen levels. Levels of Factor IX procoagulant activity and antigen (both calcium and non-calcium-dependent) are presented in Table I for all family members studied. Procoagulant activities and calciumdependent antigen levels among the five obligate heterozygotes ranged from 1.2 to $3.0 \mu \mathrm{g} / \mathrm{ml}$ and from 1.3 to $2.7 \mu \mathrm{g} / \mathrm{ml}$, respectively. Non-calcium-dependent antigen levels as determined by radioimmunoassay (7), were from 1.3 to $3.5 \mu \mathrm{g} / \mathrm{ml}$. Baseline plasmas from the four affected family members tested exhibited $<1 \%$ of normal procoagulant activity while their calcium-dependent antigen levels were readily measurable with levels between 24 and $36 \mathrm{ng} / \mathrm{ml}$. Non-calcium-dependent antigen levels determined from identical plasma samples were borderline to undetectable $(<4.0$ to $9.2 \mathrm{ng} / \mathrm{ml})$ and only background radioactivity $(<2.0 \mathrm{ng} / \mathrm{ml})$ was noted in an immunoradiometric assay 


\begin{tabular}{|c|c|c|c|c|c|}
\hline \multirow[b]{3}{*}{$\begin{array}{l}\text { Family } \\
\text { member }\end{array}$} & \multirow[b]{3}{*}{ Age } & \multicolumn{3}{|l|}{ Plasma } & \multirow{3}{*}{$\begin{array}{l}\text { Urine } \\
\text { IX:Ag } \\
\text { Calcium-dependent }\end{array}$} \\
\hline & & \multirow[b]{2}{*}{ IX:C } & \multicolumn{2}{|l|}{ IX:Ag } & \\
\hline & & & $\begin{array}{l}\text { Calcium- } \\
\text { dependent }\end{array}$ & $\begin{array}{l}\text { Non-calcium- } \\
\text { dependent }\end{array}$ & \\
\hline & & $U / d l$ & $\mu g / m l(U / d l)$ & $\mu g / m l(U / d l)$ & $\mu g / m l(U / d l)$ \\
\hline $\mathrm{I}-1$ & 59 & 65 & $2.7(68)$ & $3.12(78)^{*}$ & $0.010(0.3)$ \\
\hline II-1 & 37 & 75 & $3.5(87)$ & $3.84(96)^{*}$ & $0.002(<0.05)$ \\
\hline II-2 & 35 & 31 & $1.3(33)$ & $1.32(33)$ & ND \\
\hline II-4 & 31 & 50 & $1.7(42)$ & $1.84(46)^{*}$ & $0.040(1.0)$ \\
\hline II-5 & 29 & 75 & $2.1(52)$ & $3.52(88)^{*}$ & $0.068(1.7)$ \\
\hline II-6 & 27 & 45 & $1.6(40)$ & $1.68(42)^{*}$ & $0.036(0.9)$ \\
\hline III-3 & 10 & 95 & ND & ND & $0.016(0.4) \ddagger$ \\
\hline III-4 & 4 & $<1$ & ND & ND & $0.092(2.3) \S$ \\
\hline III-5 & 1 & ND & ND & ND & $<0.002(<0.05)$ \\
\hline III-6 & 8 & $<1$ & $0.034(0.9)$ & $0.008(0.2) \S$ & $0.120(3.0) \S$ \\
\hline III-7 & 5 & $<1$ & $0.024(0.6)$ & $0.008(0.2) \S$ & $0.064(1.6) \S$ \\
\hline III-8 & 5 & $<1$ & $0.020(0.5)^{\prime \prime}$ & $0.008(0.2) \S$ & $0.120(3.0) \S$ \\
\hline III-9 & 3 & $<1$ & $0.024(0.6)$ & $<0.004(<0.10) \S$ & $0.160(4.0) \S$ \\
\hline
\end{tabular}

Abbreviations used in this table are: IX:C, Factor IX procoagulant activity; IX:Ag, Factor IX antigen level; ND, not determined. Unless otherwise specified, levels are from assays using polyclonal antibody fractions as both the solid-phase and labeled species (as described in the experimental section and reference 13). Normal, citrated plasma pools contain $100 \mathrm{U} / \mathrm{dl}$ which corresponds to $4 \mathrm{ng} / \mathrm{ml}$ Factor IX antigen. Family members are as represented in Fig. 1. * Determined by radioimmunoassay with polyclonal rabbit anti-Factor IX (7). $¥$ Mean of three separate first morningvoided specimens (range was $10-20 \mathrm{ng} / \mathrm{ml}$ ). § The non-calcium-requiring polyclonal antibody fraction does show slightly more binding in the presence of calcium (19) such that the plasma levels observed may simply reflect presence of the calcium-dependent conformational (Gla) region in these samples. None of the affected members' plasmas or urines (the latter, even after concentration 100-fold) contained non-calcium-dependent antigen using immunoradiometric assay with the monoclonal antibody (3) which was sensitive to $2 \mathrm{ng} / \mathrm{ml}$ (see text). "A perinatal cord plasma sample previously tested was thawed and contained $20 \mathrm{ng} / \mathrm{ml}$ calcium-dependent and $4 \mathrm{ng} / \mathrm{ml}$ non-calcium-dependent IX:Ag by assays with polyclonal antibody fractions.

using the monoclonal non-calcium-requiring antibody for the solid phase and ${ }^{125}$ I-polyclonal calcium-requiring anti-Factor IX in the final incubation.

Urinary Factor IX antigen levels. Levels of urinary Factor IX antigen as determined by calcium-dependent immunoradiometric assay range from 64 to $160 \mathrm{ng} / \mathrm{ml}$ among those affected individuals studied (Table I). Antigen levels were measurable in the unconcentrated urine of all four obligate heterozygotes tested (I-1, II-4-6); these ranged from 10 to $68 \mathrm{ng} / \mathrm{ml}$. Unconcentrated urine was studied from two female family members (III-3 and III-5) whose carrier status had not yet been determined. Family member III-3 exhibited urinary calcium-dependent antigen levels from 10 to $20 \mathrm{ng} / \mathrm{ml}$ in three different urine samples while antigen was undetectable in a single first morning-voided specimen from her female sibling (member III-5). Calcium-dependent Factor IX antigen could be detected in unconcentrated urine from three normal volunteers $(10-17 \mathrm{ng} / \mathrm{ml})$. In six other normal subjects, antigen was only detectable after 10 -fold concentration where levels were between 10 and $60 \mathrm{ng} / \mathrm{ml}$.

Immunoassays in which the non-calcium-requiring monoclonal anti-Factor IX was employed as the adsorbing antibody, and ${ }^{125} \mathrm{I}$-polyclonal calcium-requiring anti-Factor IX was employed as the labeling antibody did not detect antigen in urine from affected individuals even after 200 -fold concentration and immunoaffinity purification as described in Methods. The antigenic determinant to which this non-calcium-requiring monoclonal antibody binds was detectable at a level of $480 \mathrm{ng} /$ $\mathrm{ml}$ in concentrated and immunoaffinity purified urine from the one normal subject tested. The same normal preparation $(\sim 500$ fold concentrated) had $1.72 \mu \mathrm{g} / \mathrm{ml}$ by the calcium-dependent immunoassay with polyclonal antibody.

Concentration and immunoaffinity purification of urinary Factor IX antigen. In preliminary studies employing pressure dialysis as a means of concentrating urine, it was found that nearly all of the urinary Factor IX antigen, as determined by calcium-dependent immunoradiometric assay, was retained by membranes with a 10,000 -mol-wt exclusion pore size. Urines from four patients (III-4, III-6, III-8, III-9) and four heterozygotes (I-1, II-4-6) were concentrated 100-200-fold with a yield of Factor IX antigen which was $70-95 \%$ of the starting total antigen units (Table II).

In five separate calcium-dependent adsorption-EDTA elutions of urinary Factor IX antigen (two affected individuals, two

Table II. Calcium-dependent Urinary Antigen Levels in Family Member III-9 as a Function of Concentration

\begin{tabular}{cc}
\hline Magnitude of concentration & $\begin{array}{l}\text { Calcium-dependent urinary } \\
\text { Factor IX antigen }\end{array}$ \\
\hline & $\mu \mathrm{g} / \mathrm{ml}$ \\
Unconcentrated & 0.16 \\
4-fold & 0.56 \\
20-fold & 3.44 \\
185-fold & 28.4 \\
\hline
\end{tabular}


obligate heterozygotes, and one normal subject), yields of calcium-dependent antigen in the EDTA eluate varied from 30 to $90 \%$ of the total number of Factor IX antigen units applied to the column. Void volumes and washes only contained up to $5 \%$ of the total starting urinary Factor IX antigen.

Characterization of urinary Factor IX antigen by Western blotting. Immunoaffinity-purified urinary Factor IX antigen was subjected to polyacrylamide slab gel electrophoresis, blotted onto nitrocellulose, and radiolabeled as described in Methods. Lanes labeled with ${ }^{125} \mathrm{I}$-non-calcium-requiring monoclonal anti-Factor IX failed to demonstrate any antigen in urine from affected individuals. Fig. 2 shows typical autoradiographs obtained after radiolabeling of Western blots with ${ }^{125}$ I-polyclonal calcium-requiring anti-Factor IX. After reduction of purified urinary Factor IX antigens, ${ }^{125}$ I-polyclonal calcium-requiring anti-Factor IX identified a single band of $\sim 36,000 \mathrm{~mol} w \mathrm{wt}$ from the urines of four affected individuals. A 62,000-mol-wt band as well as an

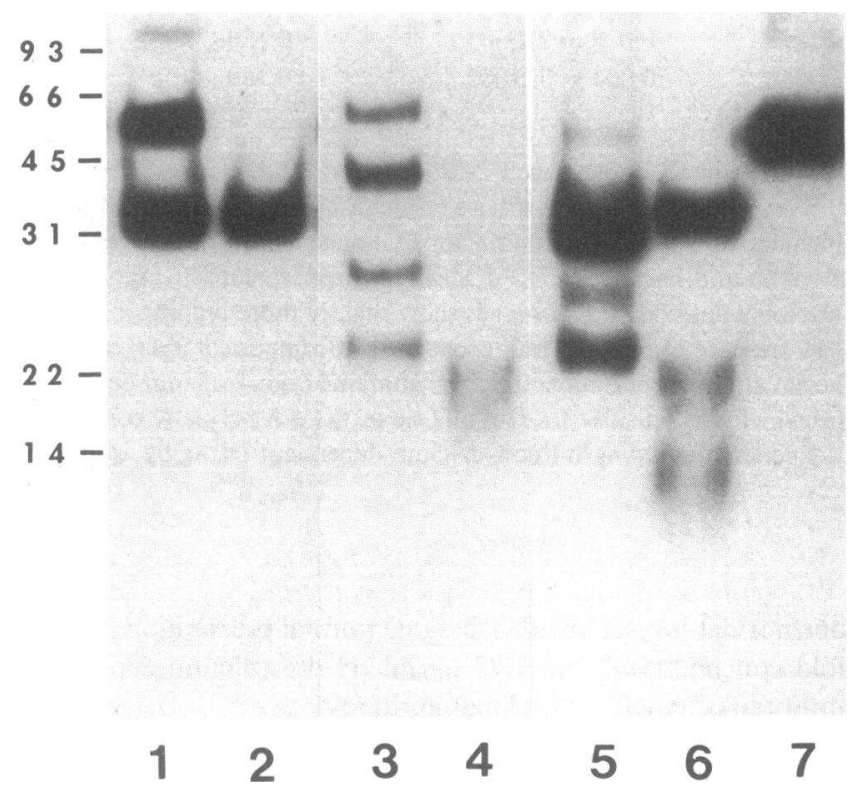

Figure 2. Characterization of urinary Factor IX antigen by Western blotting. Concentrated and immunoaffinity-purified normal and hemophilic antigen were electrophoresed in polyacrylamide slab gels, blotted, and autoradiographed after labeling with ${ }^{125}$ I-polyclonal calcium-dependent anti-Factor IX. Lanes 1 and 2 represent urinary Factor IX antigen from an affected family member (III-9), electrophoresed without or after reduction, respectively. The single 36,000 -molwt band observed in lane 2 was noted in the three other affected family members studied, as were variable amounts of the two higher molecular weight species (lane 1 ) in blots of unreduced samples. Lanes 3 and 4 are from a urinary Factor IX sample from a normal volunteer, again electrophoresed without or after reduction, respectively. This same pattern was also noted on samples form urines of family members II-1 (a nonheterozygote) and III-3 (not shown). Nonreduced and reduced samples from obligate heterozygote II- 6 are depicted in lanes 5 and 6; a similar pattern was noted for the three other obligate heterozygotes tested. Lane 7 is native plasma Factor IX, immunoaffinitypurified from a small volume of plasma from family member I-1, for reference. The autoradiographs were developed after the following exposure times: lanes 1 and 2 (each containing the equivalent of $40 \mathrm{ng}$, calcium-dependent Factor IX antigen), $1 \mathrm{~h}$; lanes 3 and 4 (each representing $2.4 \mathrm{ng}$ antigen), $96 \mathrm{~h}$; lanes 5 and 6 (6 ng each), and lane 7 $(3.2 \mathrm{ng}), 120 \mathrm{~h}$. Molecular weight markers (see Methods) migrated as indicated to the left; the origin is at the top and anodal migration of the tracking dye at the bottom of the gels. additional higher molecular weight species were noted on autoradiographs of all unreduced patient samples. Reduced antigen from normal urine migrated as a broad, 15,000-20,000-mol-wt band. Nonreduced normal urinary Factor IX antigen migrates as four distinct bands with mol wts ranging from 24,000 to 62,000 . Interestingly, reduced samples of urinary Factor IX antigen from the four obligate carriers tested (I-1, II-4-6) demonstrated both the normal 15,000-20,000-mol-wt band as well as a more prominent 36,000 -mol-wt species characteristic of reduced patient urinary Factor IX. 100-fold concentrated urine from family members II- 1 and III-3 were electrophoresed following reduction and demonstrated only the normal 15,00020,000-mol-wt band (not shown).

Incubations of Factor $I X$ in urines. To determine the stability of Factor IX's size and antigenicity in urine, trace amounts of ${ }^{125}$ I-labeled normal isolated protein were incubated in two normal, one heterozygote, or three patient urines for $4 \mathrm{~h}$ at $37^{\circ}$. After reduction and electrophoresis on $10 \%$ polyacrylamide slab gels in sodium dodecyl sulfate, all of the ${ }^{125} \mathrm{I}$-Factor IX samples $(3,000 \mathrm{cpm}$ in $50 \mu \mathrm{l})$ migrated as the same size as the unincubated control; control incubations in 0.1 M MES buffer at pH 5.0, 5.5 , or 6.0 were likewise uncleaved. For the antigenicity experiments, microtiter wells were coated as for the first step of immunoradiometric assays using monoclonal and polyclonal noncalcium-requiring antibodies or the calcium-requiring polyclonal antibody (see Methods). ${ }^{125}$ I-Factor IX was added to separate aliquots of each of the above urines $(50,000 \mathrm{cpm}$ to $60 \mu \mathrm{l})$ and incubated for $4 \mathrm{~h}$ at $37^{\circ}$. Samples were diluted sixfold in the assay dilution buffer with albumin and calcium, and incubated in the antibody-coated wells for $3 \mathrm{~h}$ at $37^{\circ}$. Binding of ${ }^{125} \mathrm{I}$ Factor IX was between 15 and $40 \%$ of the counts added. For six incubated urine samples, binding of radioactivity averaged 95-99\% of binding by nonincubated controls for the three antibodies. Incubations in $0.1 \mathrm{M}$ MES buffer at pH 5.5 or 6.0 also showed no change in antigen binding. After incubation at $37^{\circ} \mathrm{C}$ at pH 5.0, binding to the calicum-requiring polyclonal antibody was reduced to $33 \%$ of its control whereas binding to the other two antibody preparations was essentially unaltered. Thus, the antigenicity of the calcium-dependent epitopes in Factor IX was reduced by incubation at $37^{\circ}$ at $\mathrm{pHs}$ just below those found in the urine samples, but was unaltered in the actual urine samples studied.

\section{Discussion}

A partial gene deletion which removes the DNA sequences coding for amino acids 85-195 (exons V and VI, Fig. 3) is responsible for severe hemophilia B in the pedigree studied (6). Without activation cleavage sites, any resulting mutant Factor IX would be unable to generate the necessary free alpha-amino group to become an active serine protease (2). Without this activation component, these patients' plasmas could not form Factor IXa.

In contrast to other patients with gene deletions as a cause of severe hemophilia $B(4,5)$, affected members of this pedigree have not developed inhibitors. This may be due to the trace levels of partial Factor IX circulating. These levels cannot be explained by traces of transfused Factor IX since plasma samples were obtained between 2 wk and 2 mo after the last factor replacement therapy. In addition, the preserved calcium-dependent antigenic determinants may represent the predominant antigens that are potentially immunogenic $(18,19)$. Alternatively, the 


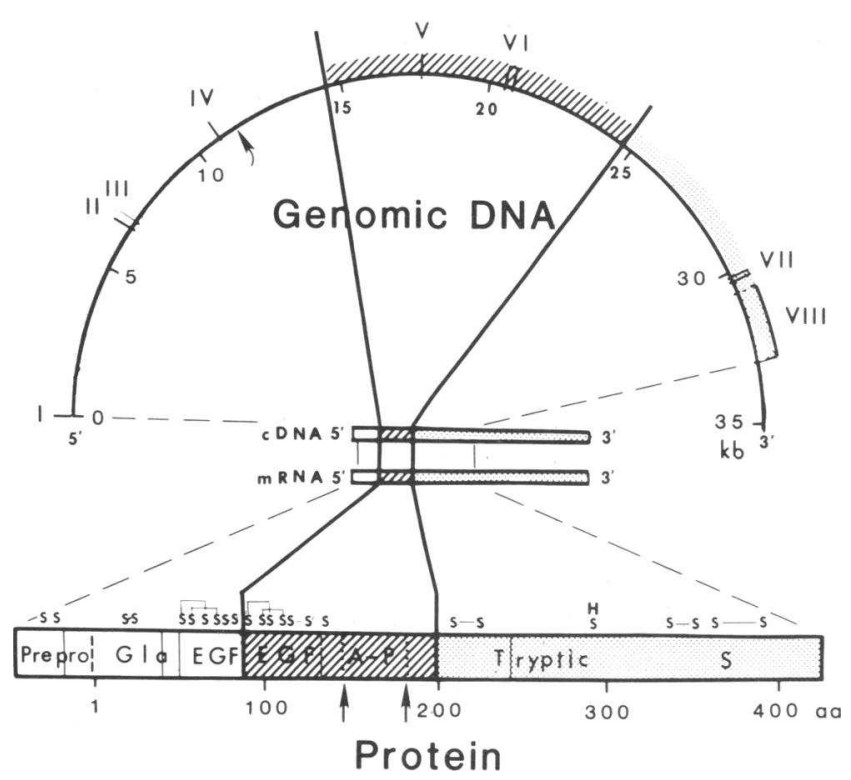

Figure 3. Representation of the gene deletion. The gene $(16,17)$ is represented as a semicircle with exons identified by Roman numerals; the corresponding protein is displayed as the rectangular bar in the lower part of the figure (2). The partial gene deletion (cross-hatched segment) is $\sim 10 \mathrm{~kb}$ in length and begins within the intron $3^{\prime}$ to exon IV, spans exons V and VI, and extends well into the subsequent intron (6). The curved arrow represents the Taq I polymorphic cleavage site. The native amino acid sequences corresponding to the deleted gene segment involve residues 85-195 (crossed-hatched). If exons VII and VIII, which are $3^{\prime}$ to the deletion, are intact and transcribed (stippled portion), an unpaired sulfhydryl group (cysteine 289) would be present in the mutant Factor IX protein. However, the exact nature of the carboxy-terminal portion as specified by coding sequences $3^{\prime}$ to the deleted DNA segment remains to be elucidated (see Discussion).

tendency to form inhibitors, independent of the defect, may simply be absent in the seven patients of this pedigree.

While the partial Factor IX antigen has been demonstrated in affected individuals from this pedigree, reasons for its higher concentration in urine as opposed to plasma are less clear. Increased renal excretion of abnormal Factor IX might be due to an absence of oligosaccharide side-chains and its smaller size. Alteration of the mutant protein within the patients' urinary tracts may have occurred, but the single immunoreactive species seen on the electrophoresed and blotted reduced patient urines suggests that any in vivo processing would have had to have been nearly complete. Furthermore, normal Factor IX was neither cleaved nor became less antigenic after incubation in urine samples. The fact that the mutant Factor IX circulates at all may well be due to its disulfide bonding or, perhaps, the tendency of amino-terminal fragments to form noncovalent dimers with calcium, a property well recognized in prothrombin. In addition, the primary processing of infused normal Factor IX is extrarenal (20). Thus, the low levels of both plasma and urinary Factor IX antigen in these patients are best explained by decreased secretion from the hepatocytes or increased reticulo-endothelial processing of the mutant gene product.

The structure of the mutant Factor IX remains to be determined. Its reaction with antibodies specific for the calcium-dependent conformation argues that the amino-terminal (Gla) region, as a product of the second and third exons, is represented. Considerations of the polypeptide portion carboxy-terminal to the deletion site, however, must account for the size of the urinary fragments observed both before and after reduction of disulfide bonds. The most simple explanation of the defect is that exons VII and VIII are transcribed normally. A 36,000-mol-wt mutant Factor IX would be predicted from the loss of Asn-linked carbohydrate and a quarter of the amino acid sequence. Such a species would possess a free, unpaired sulfhydryl group at residue 289 (Fig. 3). A second mechanism to consider is a frame shift. This would actually be predicted since exon IV ends with the first base of a triplet which normally includes the first two bases of exon $\mathrm{V}$ to form the codon for residue 85; exon VII begins in phase with a complete triplet $(16,17)$. A new cysteine residue would be coded for in the second, shifted position. However, because the sixth, shifted codon would be TAA (a stop signal) the resulting peptide should only have a molecular weight of around 9,000. A third possibility is a new splice junction, occurring where the introns on either side of the deletion join. Here, a new nonsense peptide might be specified to compose the carboxy-terminal portion of the species observed; it too could contain an unpaired cysteine which could bind to other peptides. Disulfide formation would probably occur within the hepatocyte and could not be accounted for by simple dimers of a 36,000mol-wt species (Fig. 2). Unfortunately, there is insufficient purified mutant protein for structural analysis. It is anticipated that determination of the exact nucleotide base sequence $5^{\prime}$ and $3^{\prime}$ to the deleted segment (6), will allow prediction of the mutant carboxy-terminal structure. The urinary species could then serve as a reagent to help localize properties of Factor IX that either are or are not represented in the partial protein.

The detection of Factor IX antigen in the concentrated urines from normal subjects was surprising. Previous radioimmunoassays (20-40-fold less sensitive than current methods) found that some patients with nephrotic syndrome, but not normal individuals, excrete detectable Factor IX antigen (21; Thompson, A. R., unpublished data, 1980). Furthermore, levels from calcium-dependent immunoassays suggest that these determinants are represented to a greater extent in normal urine than are epitopes recognized by non-calcium-requiring antibodies. This may be analogous to the amino-terminal fragment of prothrombin which has recently been detected in normal urines and at higher levels in urines from pregnant women (22). The latter could be due to the amniotic fluid serving as a reservoir for the prothrombin fragment (13).

The calcium-dependent Factor IX urinary metabolites from normal individuals were present in lower concentrations than in patient urines. In addition, the normal antigen was qualitatively distinct from the hemophilic urinary antigen on electrophoresis (Fig. 2) and in reactivity with the non-calcium-requiring monoclonal antibody to Factor IX. This antibody recognizes an antigenic determinant on the heavy chain of Factor IXa (3) which was detectable in purified normal, but not patient, urine fractions. The latter remained $<2 \mathrm{ng} / \mathrm{mg}$ in patient samples concentrated 200 -fold. These data suggest that the heavy chain epitope for this antibody resides somewhere between residues 181 and 195 of the native protein; alternatively, the antigenic determinant for this monoclonal antibody may be masked, or is simply absent due to altered transcription $3^{\prime}$ to the deleted gene segment.

The Western blots of purified urinary antigen from the four obligate heterozygotes studied share features found on radiolabeled blots from both normal and patient urines (Fig. 2). These shared features support the finding that Factor IX DNA from both the normal and hemophilic genes is expressed in these 
women and results in a pattern that is a hybrid of normal and patient blotted material. Family member II- 1 is a known, nonheterozygote by virtue of the fact that she does not manifest the linked Taq 1 restriction fragment length polymorphism which her sisters and mother do (6). Both she and her niece (III-3, Fig. 1), demonstrate only normal urinary Factor IX fragments on autoradiographs. The youngest female (III-5) lacks detectable calcium-dependent antigen in unconcentrated urine whereas the four obligate heterozygotes tested all had at least $10 \mathrm{ng} / \mathrm{ml}$. Although DNA samples on subjects III-3 and III-5 have not been studied, the immunoassays demonstrate that analysis of urine samples can be used to recognize heterozygosity for the hemophilic gene in this family. Furthermore, such testing is more sensitive and specific than either Factor IX clotting activity or antigen level determinations from plasma samples of these women.

\section{Acknowledgments}

Gifts of purified human Factor IX from Dr. Walter Kisiel and monoclonal, anti-Factor IX from Dr. Kenneth Smith are greatly appreciated.

We also thank Ms. Ann Weinmann and Ms. Lucy Suzuki for their excellent technical assistance, as well as Ms. Daphne Matlick for secretarial assistance in the preparation of the manuscript.

This work was performed while Dr. Bray was a National Hemophilia Foundation Judith Graham Pool Fellow and was supported in part by American Heart Association of Washington grant-in-aid 84-WA526; National Heart, Lung, and Blood Institute grant HL-31193; and a Poncin Fund Award from the Sea-First Corporation of Seattle.

\section{References}

1. Roberts, H. R., and R. Cromartie. 1984. Overview of inhibitors to factor VIII and IX. Prog. Clin. Biol. Res. 150:1-18.

2. Thompson, A. R. 1985. Structure, function and molecular defects of factor IX. Blood. 67:565-572.

3. Thompson, A. R. 1983. Monoclonal antibody to an epitope on the heavy chain of factor IX missing in three hemophilia B patients. Blood. 62:1027-1034.

4. Giannelli, F., K. H. Choo, D. J. G. Rees, Y. Boyd, C. R. Rizza, and G. G. Brownlee. 1983. Gene deletions in patients with haemophilia $B$ and anti-factor IX antibiodies. Nature (Lond.). 303:181-182.

5. Peake, I. R., B. L. Furlong, and A. L. Bloom. 1984. Carrier detection by direct gene analysis in a family with haemophilia B (factor IX deficiency). Lancet. i:242-243.

6. Chen, S.-H., S. Yoshitake, P. F. Chance, G. L. Bray, A. R. Thompson, C. R. Scott, and K. Kurachi. 1985. An intragenic deletion of the
Factor IX gene in a family with hemophilia B. J. Clin. Invest. 76:21612164.

7. Thompson, A. R. 1977. Factor IX antigen by radioimmunoassay. Abnormal Factor IX protein in patients on warfarin therapy and with hemophilia B. J. Clin. Invest. 59:900-910.

8. Kasper, C. K. 1984. Measurement of factor VIII Inhibitors. Prog. Clin. Biol. Res. 150:87-98.

9. Proctor, R. R., and S. I. Rapaport. 1961. The partial thromboplastin time with kaolin. A simple screening test for first stage plasma clotting deficiencies. Am. J. Clin. Pathol. 36:212-219.

10. Kessler, S. W. 1975. Rapid isolation of antigen from cells with a staphylococcal protein A antibody adsorbent: parameters of the interaction of antibody-antigen complexes with protein A. J. Immunol. 115: 1617-1624.

11. Liebman, H. A., S. A. Limentani, B. C. Furie, and B. Furie. 1985. Immunoaffinity purification of factor IX (Christmas factor) by using conformation-specific antibodies directed against the factor IX-metal complex. Proc. Natl. Acad. Sci. USA. 82:3879-3883.

12. Smith, K. J. 1985. Monoclonal antibodies to coagulation factor IX define a high frequency polymorphism by immunoassays. Am. $J$. Hum. Genet. 37:668-679.

13. Thompson, A. R. 1984. Factor IX and prothrombin in amniotic fluid and fetal plasma: constraints on prenatal diagnosis of hemophilia B and evidence of proteolysis. Blood. 64:867-874.

14. Weber, K., and M. Osborn. 1969. The reliability of molecular weight determinations by dodecyl sulfate-polyacrylamide gel electrophoresis. J. Biol. Chem. 244:4406-4412.

15. Towbin, H., T. Staehelin, and J. Gordon. 1979. Electrophoretic transfer of proteins from polyacrylamide gels to nitrocellulose sheets. Proc. Natl. Acad. Sci. USA. 76:4350-4354.

16. Anson, D. S., K. H. Choo, D. J. G. Rees, F. Giannelli, J. A. Huddleston, and G. G. Brownlee. 1984. The gene structure of human anti-haemophilic factor IX. EMBO (Eur. Mol. Biol. Organ.) J. 3:10531060.

17. Yoshitake, S., B. G. Schach, D. C. Foster, E. W. Davie, and K. Kurachi. 1985. Nucleotide sequence of the gene for human factor IX (anti-hemophilic factor B). Biochemistry. 24:3736-3750.

18. Briet, E., H. M. Reisner, and H. R. Roberts. 1984. Inhibitors in Christmas disease. Prog. Clin. Biol. Res. 150:123-139.

19. Bray, G. L., A. F. Weinmann, and A. R. Thompson. 1986. Calcium-specific immunoassays for Factor IX: reduced levels of antigen in patients with vitamin K disorders. J. Lab. Clin. Med. 107:269-278.

20. Smith, K. J., and A. R. Thompson. 1981. Labeled factor IX kinetics in patients with hemophilia B. Blood. 58:625-629.

21. Thompson, A. R. 1982. Factor XII and other hemostatic protein abnormalities in nephrotic syndrome patients. Thromb. Haemostasis. 48:27-32.

22. Bezeaud, A., and M.-C. Guillin. 1984. Quantitation of prothrombin activation products in human urine. Br. J. Haematol. 58:597606 . 